\title{
Screening of Pigeonpea [Cajanus cajan (L.) Millsp.] against Gram Pod Borer, Helicoverpa armigera (Hubner (Lepidoptera:Noctuide) in Long Duration Pigeonpea genotypes
}

\author{
Rohit Sharma* and Ram Keval
}

Department of Entomology and Agricultural Zoology, Institute of Agricultural Sciences, Banaras Hindu University, Varanasi, India

*Corresponding author

\begin{tabular}{|c|}
\hline Keywords \\
\hline $\begin{array}{l}\text { Pigeon pea, pod } \\
\text { borer, screening, } \\
\text { damage, } R B D\end{array}$ \\
\hline Article Info \\
\hline $\begin{array}{l}\text { Accepted: } \\
22 \text { April } 2021 \\
\text { Available Online: } \\
10 \text { May } 2021\end{array}$ \\
\hline
\end{tabular}

Keywords

Pigeon pea, pod borer, screening, damage, RBD

Article Info

Accepted:

10 May 2021
A B S T R A C T

The pigeonpea was infested with the number of insect pests at various stage of crop growth. Out of which the incidence pattern $H$. armigera of was studied. The result of the investigation pertaining to the "Screening of pigeonpea [Cajanus cajan (L.) Millsp.] against Gram pod borer, H. armigera (Hubner (Lepidoptera:Noctuide) in long duration Pigeonpea genotypes" was carried out in 2018-19 at the Agricultural Research Farm, Institute of Agricultural Sciences, Banaras Hindu University, Varanasi. This insect was studied during reproductive phase of the crop during 2018-19 with the Randomized Block design. In all genotypes except AVT1-708 under trail the first incidence of gram pod borer H.armigera was observed in the 4th standard week of 2018-19. The population of pod borers in all genotypes persisted from the 4th standard week of 2018-19 to the 12th standard week of 2018-19. Maximum population of (0.69 larva/plant) in the MAL-13 (AVT1) genotype followed in the first week of 2018-19 The pooled mean population of gram pod borer was recorded highest in the genotype MAL-13 (AVT1) (check) (0.92 larva/plant) lowest in AVT1-707 (0.41 larva/plant). Pod damage caused by gram pod borer pod damage in cultivar genotype AVT2-907 ranging from 3.67 per cent to 7.67 per cent in cultivar MAL-13(AVT-1). The percentage of grain damage on various genotypes caused by Gram pod borer. The damage ranged from 0.79 per cent in the genotype AVT2-907 to 3.80 per cent in the genotype AVT1-706. The damage caused to the grain by the genotype for long-duration pigeonpea has been primarily attributed to pod fly, pod bug and gram pod borer. This ranged from $12.68 \%$ to $30.52 \%$ for pod fly, $4.71 \%$ to $8.93 \%$ for pod bug and $0.79 \%$ to $3.80 \%$ for gram pod borer.. In AVT1-708 the cereal yield of different genotypes was from $617 \mathrm{~kg}$ / ha to $1434 \mathrm{~kg}$ / ha with AVT1-707 genotype. 


\section{Introduction}

Pigeonpea [Cajanus cajan (L.) Millspaugh] is a major tropical and subtropical climate grain legume crop cultivated on nearly 4.8 million hectares covering 22 Asian, African and Caribbean countries worldwide. In pigeon pea production, India has a virtual monopoly accounting for 90 percent of total world production. In India, it covers a surface of 3.88 million acres (E-Pulses IIPR, 2015-16) for production of 3.17 million tonnes. It is usually Cultivated on marginal land and intercropped with other pulses. However, as sole crops are gaining cash crop status, farmers grow pigeonpea.

Pigeonpea [Cajanus cajan (L.) Millspaugh] is a short-lived permanent shrub, grown through custom as a grain legume crop in tropical and subtropical areas. Pigeonpea is the annual grain legume production of pigeons. It's named red gram (Red) and Congo (English), tur and Arhar (Hindi), and is mainly cultivated as foodstuff. Dry whole seed, split seed (dhal) and dehulled seed are used to cook various dishes. In addition to its use as a food crop, the plants also cultivate lake insects, such as forages, fuel, stomach, basket-making, etc., Pigeonpea has a deep root system that enables them to withstand the drought and are cultivated on mountain slopes to tie the soil and to reduce the erosion of the soil.

Pigeonpea is lowly grown because of its deeproot system, therefore extensively used with cereals, like millets, sorghum and maize in inter-cropping systems and is also a good way of improving fertility in fallows. During the early vegetative stage, pigeonpea grows slowly and does not interfere with accompanying crops. The following crops are harvested. Pigeonpea continue to grow after harvesting the accompanying crop, and they can fill the land with the appearance of a single crop (AICRP).
Many effort has been made to recognize and integrate these resistances into agronomical crops to identify resources resistant to the most important insect pest, especially Helicoverpa armigrera (Hubner) During the last decade, pigeonpea productivity in India did not increase considerably. Due to insect pest damage is one of the main reasons for low productivity. Almost 90 percentage of crops with medium-to long duration cultivars are cultivated in rainfed conditions. For irrigated settings, short term varieties are suitable. Since the colonial pigeons are growing under many agroclimate conditions and different crops, pigeon pests Sachan et al., (1990) are vulnerable to many pests, although they cause relatively few serious losses of yield, and Almost 250 insect species worldwide, although relatively low in yield, belong to eight orders and 61 families. Other main pests such as are potential pesticides, and occasional significant lowers in the production of grain during long-term pork. Powder pillars include Gram pod borer Helicoverpa armigera (Hubner), tur pod fly Melanagromysa obtusa (Malloch).There is no economic damage to early or vegetative stage the main and important plagues are however the pests of flowers and pod borers. Pod fly Melanagromyza obtusa is a wide-ranging and important pigeon pea pest in Asia. It only feeds on pigeon pea, and related species, and provides a small host range. The fully-grown larvae in the pod walls emerge from this hole. This hole has a "window" that allows the adult to leave the hole.The survey carried out by ICRISAT reported damage in $22.5 \%$ pigeon peas in the north of India, $21 \%$ in the central part of India and $13.2 \%$ in the south of India (lateef and reed, 1981), while in the northwest area there were $29.7 \%, 13.2 \%$ in the north zone $24.3 \%$ and $36.4 \%$ for the south. In a survey conducted by ICRISAT the results were: Melanagromyza obtusa (malloch).The annual pigeonpea crop was projected to loss 25 to 30 percent in U.P because of pod fly 
alone (Lal and Yadav, 1987). In addition to the podfly and other insects, damage caused by pod sucking bugs has been detected in 50.000 tons of u.p annually, total grain loss due to the attacks pigeons and other legumes in Asia with several kinds and genera of. It is widespread across the tropics and the subtropics. It is a weed which is polyphagous. The adult females lay eggs singly on tender parts of the plant. The time of incubation lasts from 2-4 days. The larvae are feed on flower buds and pod. Usually visible holes are produced on pods by the entry of larvae, developing and party matured seeds are fully eaten, often a portion of the seed and test a remain un attacked. These insects penetrate the pod wall with the adult and nymphs to suck fluid from which seeds can be made. Damaged seeds are reduced and there are dark patches. In the past, the injury has been close to that of drought stress and the impact of the insect. Seeds spoiled with pods sucking bugs do not sprout or become acceptable as food.

Helicoverpa armigera is a cosmopolitan, extremely polyphagous insect that is the primary biological restriction for the increase of pigeon pea production (Lateef and Reed, 1981), targeting many crop plants of agricultural importance all over the world. H.armigera's key pest status is due to the larval preference for feeding nitrogen rich plant parts, such as reproductive structure and cultivation tips. Annual $H$. armigera pigeon pea losses were estimated to amount to more than \$300 million (Anonymous, 1992).

\section{Materials and Methods}

The field experiment was conducted on the topic"Screening of pigeonpea [Cajanus cajan (L.) Millsp.] against Gram pod borer, $H$. armigera (Hubner (Lepidoptera:Noctuide) in long duration Pigeonpea genotypes" The present investigation on the cooperative output of certain genotypes was conducted during
2018-19 at Agriculture Research Farm, Institute of Agricultural Science, Banaras Hindu University, Varanasi.

Seed sowing was done manually with spacing from row to row $(75 \mathrm{~cm})$, and spacing from plant to plant $(25 \mathrm{~cm})$.In the first 10 accessions, the field experiment was performed with 18 pigeon pea accession into a separate trial and in the second trial 8 accession was used respectively as an initial varietal trial and advanced varietal trial.

\section{Gram pod borer, H. armigera (Hubner)}

It is widespread across the tropics and the subtropics. It is a weed which is polyphagous. The adult females lay eggs singly on tender parts of the plant. The time of incubation lasts from 2-4 days. The larvae are feed on flower buds and pod. Usually visible holes are produced on pods by the entry of larvae, developing and party matured seeds are fully eaten, often a portion of the seed and test a remain un attacked.

\section{Grain damage}

The damage to the seed has been established based on the amount of seeds affected in pods that are taken for observation. This has been carried out using the formula.

$$
\begin{aligned}
& \% \text { Pod damage }=\frac{\text { Number of damaged pods }}{\text { Total number of pods }} \times 100 \\
& \% \text { Grain damage }=\frac{\text { Number of damaged grains }}{\text { Total number of grains }} \times 100
\end{aligned}
$$

\section{Grain yield}

When the crop matured, separately threshed and grain yield per plot was recorded and transformed to grain yields in $\mathrm{kg} / \mathrm{ha}$, each genotype was individually harvested. 


\section{Statistical analysis}

All data recorded have been statistically calculated according to the Randomized Block design method and population data from the insects have been transformed using a transformable square root method, and harm evaluation data have been transformed using the transformed method $\sin (\mathrm{q}=\sin -1 \mathrm{x})$. For a certain period, insect infestation has coincided with meteoric parameters such as the high temperature, minimum temperature relative moisture in the morning, relative evening wetness and rainfall in the same week, so as to create a relationship between insect infestation and weather parameters.

\section{Gram pod borer, H. armigera (Hbuner)}

Incidence of Gram pod borer during 2018-19. H.Armigera was observed in all genotype except AVT1-708 during the 4th Standard Week. The population varied significantly among the genotypes screened in the genotype MAL 13(AVT1) with a maximum population of 0.69 larva/plant followed in the first week by AVT1-704 (0.30 larval/plant), AVT1-709 (0.22 larval/plant) AVT1-705 and AVT1-706 \& AVT2-901 having population $(0.20$ larvae/plant). In all genotypes from 4th Standard Week to 12th standard Week 201819 , the H.armigera larval population persisted. During the 11th standard week, the population of the Pod borer was reported to be highest in nearly all genotypes, with a larval population of 2,05 larva / plant in genotypes of MAL 13(AVT1). During the 11th standard week accompanied by AVT1-707 (1.00 larvae / plant) and AVT1-708 (1.05 larva / plant), the smallest population of pod borer was found with genotypes MAL 13 (AVT2) (.93 larvae/plant) table No. 1.1 and 1.2. The mean pooled population of gram pod borer also differed significantly between the genotypes where the growing population was recorded in MAL 13 (AVT1) (check) (0.92 larva/plant) followed by AVT1-704 (0.82 larva/plant) followed by AVT1-709 (0.77 larva/plant) and AVT1-706 (0.74 larva/plant) followed by AVT1-701(0.65 larva/plant) followed by AVT1-705 (0.63larva/plant),AVT2-906 (0.60 larva/plant), AVT2-903 (0.59 larva/ plant) AVT1 702 (0.57larva/plant) AVT2-902 (0.51 larva/plant) AVT2-904 (0.49larva /plant) AVT2-901 \& AVT1-708 (0.47 larva/plant) AVT2-907 (0.46 larva/plant) AVT1-703 \& AVT2-905 (0.45larva /plant) MAL-13(AVT2) (0.42 larva/plant) AVT1-707(0.41 larva/plant) table No 1.1 and 1.2.

\section{Pod damage}

Different genotypes against gram pod borer showed a large difference in percent pod damage ranging from 3.67 percent in cultivar genotype AVT2-907 to 7.67 percent in cultivar MAL 13(AVT-1).

All genotypes showed a relatively lower percentage of pod damage compared to checks, MAL-13(AVT1)(7.67\%), followed by AVT1-703 (7.33), AVT2-904 (7.33), AVT1707 (7.00), AVT2-903 (7.00), AVT1-709 (6.67), AVT2-905 (6.67), MAL -13 (AVT2) (6.33), AVT1-702 (6.00), AVT2-901 (5.67), AVT1-706 (5.67), AVT1-701 (5.67), AVT1704 (5.33), AVT2-902 (5.33), AVT1-708 (4.33), AVT2-906 (4.00). In genotype AVT2907 , the lowest percentage of pod damage was recorded (3.67 per cent) table No. 1.1 and 1.2.

\section{Grain damage}

The proportion of grain damage from pod fly in different genotypes of pigeonpea during 2018-2019 was significantly different. The loss in genotype AVT2-904 ranged from $12.68 \%$ to $30.52 \%$ in genotype AVT2-907. Highest grain damage was recorded in genotype followed by AVT1-703 (29.21), AVT1-702 (26.68), AVT2-901 (26.62), AVT1-707 (23.46), AVT2-906 (23.32), 
AVT2-902 (23.16) MAL-13(AVT1) (22.28), AVT1-708(21.31), AVT1-709 (21.30), AVT1704 (20.63), AVT2-903 (18.73), AVT1-701 (17.99), AVT2-905 (17.97), MAL 13(AVT2) (16.41), AVT1-706 (15.33), percent. Lowest grain damage occurred in genotype AVT2-904 (12.68\%) followed by AVT1-705 (13.92\%) table no 1.1 and 1.2.

\section{Grain yield}

The data presented in Table No. 2.1 and 2.2 displays the grain yield of the various genotypes of pigeon pea in grain yields. The genotype AVT1-708 is $617 \mathrm{~kg} /$ ha to $1434 \mathrm{~kg} /$ ha throughout the AVT1-707 genotype. The genotypes AVT1-704 and AVT1-706 and AVT1-709 \& AVT2-901, AVT2-907, MAL13 (AVT2), AVT1-702 \& AVT1-705, AVT1703, AVT2-902, AVT2-906, AVT2-903, AVT2-905, AVT2-904 and MAL 13(AVT1) show comparatively higher yields, i.e., 1233 $\mathrm{kg} / \mathrm{ha}, 1025 \mathrm{~kg} / \mathrm{ha}, 1017 \mathrm{~kg} / \mathrm{ha}, 1000 \mathrm{~kg} / \mathrm{ha}$, 900kg/ha, $850 \mathrm{~kg} / \mathrm{ha}, \quad 840 \mathrm{~kg} / \mathrm{ha}, \quad 767 \mathrm{~kg} / \mathrm{ha}$, $748 \mathrm{~kg} / \mathrm{ha}, 717 \mathrm{~kg} / \mathrm{ha}$ and $667 \mathrm{~kg} / \mathrm{ha}$ respectively as compared to AVT1-708 giving yield $617 \mathrm{~kg} / \mathrm{ha}$.

\section{Results and Discussion}

During 2018-19, in the research farm of the Institute of Agricultural Sciences, Banaras Hindu University, Varanasi, field experimentations on various long-duration genotypes of pigeonpea were conducted to test the Screening of pigeonpea [Cajanus cajan (L.) Millsp.] against Gram pod borer, $H$. armigera (Hubner (Lepidoptera:Noctuide) in long duration Pigeonpea genotypes. In order to determine the population of major insect pests on different genotypes of pigeon pigeon and risk analysis of percent pod and grain damage by pod pest complex, eighteen genotypes have been risen under unsupervised situations.

Performance in yield $(\mathrm{kg} / \mathrm{ha}$ ) was also reported at crop harvest. In all genotypes except AVT1708 under trail the first incidence of gram pod borer H.armigera was observed in the 4th standard week of 2018-19. The population of pod borers in all genotypes persisted from the 4th standard week of 2018-19 to the 12th standard week of 2018-19.

Table.1 The following 18 genotypes/varieties have been screened against infestation of pigeon pea pod pest complex.

AVT-1

AVT1-701

AVT1-702

AVT1-703

AVT1-704

AVT1-705

AVT1-706

AVT1-707

AVT1-708

AVT1-709

MAL-13 (Check)
AVT-2

AVT2-901

AVT2-902

AVT2-903

AVT2-904

AVT2-905

AVT2-906

AVT2-907

MAL-13 (Check) 
Table.2 Population of gram pod borer [H. armigera (Hubner)] on some pigeonpea genotypes during Kharif 2018-19:

H.armigera larvae per plant

\begin{tabular}{|c|c|c|c|c|c|c|c|c|c|c|}
\hline Genotypes & 4th SW & 5th SW & 6th SW & 7th SW & 8th SW & 9th SW & 10th SW & 1th SW & 12th SW & rage \\
\hline 1711 & $.18(1.086)$ & $0.27(1.127)$ & $0.3(1.140)$ & $.32(1.149)$ & $.34(1.158)$ & $.88(1.371)$ & $1.2(1.483)$ & $1.37(1.539)$ & $.98(1.407)$ & 0. \\
\hline AVI. & $.06(1.030)$ & $0.20(1.095)$ & $0.26(1.122)$ & $.3(1.140)$ & $.38(1.175)$ & $.8(1.342)$ & $.95(1.396)$ & $1.21(1.487)$ & $.93(1.389)$ & 0. \\
\hline AVI. & $.03(1.015)$ & $0.12(1.058)$ & $0.3(1.140)$ & $.25(1.118)$ & $.25(1.118)$ & $.5(1.224)$ & $.360)$ & $1.12(1.456)$ & $.6(1.265)$ & 0.4 \\
\hline AVT1 & $.140)$ & $0.16(1.077)$ & $0.36(1.166)$ & $.44(1.200)$ & $0.56(1.249)$ & $1.16(1.470)$ & $1.65(1.628)$ & $1.89(1.700)$ & $.9(1.378)$ & 0.8 \\
\hline AVT1-705 & $.095)$ & $0.2(1.095)$ & $0.26(1.122)$ & $0.36(1.166)$ & $0.37(1.170)$ & $.83(1.353)$ & $1.2(1.483)$ & $1.3(1.517)$ & $.94(1.393)$ & 0.6 \\
\hline VVT1-706 & $.2(1.095)$ & $0.3(1.140)$ & $0.18(1.086)$ & $0.40(1.183)$ & $0.55(1.245)$ & $.9(1.378)$ & $1.32(1.523)$ & $1.75(1.658)$ & $1.03(1.425)$ & 0.7 \\
\hline VVT1-707 & $.01(1.005)$ & $0.04(1.020)$ & $0.16(1.077)$ & $0.24(1.114)$ & $0.26(1.122)$ & $.65(1.285)$ & $.77(1.330)$ & $1(1.414)$ & $.55(1.245)$ & 0.4 \\
\hline AVT1-708 & $0(1.000)$ & $0.01(1.005)$ & $0.26(1.122)$ & $0.35(1.162)$ & $0.28(1.131)$ & $.62(1.273)$ & $.83(1.353)$ & $1.05(1.432)$ & $.8(1.341)$ & 0. \\
\hline AVT1-709 & $.22(1.105)$ & $0.4(1.183)$ & $0.49(1.221)$ & $.37(1.170)$ & $.5(1.225)$ & $.96(1.400)$ & $1.24(1.497)$ & $1.57(1.603)$ & $1.2(1.483)$ & 0.7 \\
\hline IVIAL-IJ & $.69(1.300)$ & $0.43(1.196)$ & $0.29(1.136)$ & $.46(1.208)$ & $.69(1.300)$ & $1.04(1.428)$ & $1.65(1.628)$ & $2.05(1.746)$ & $1.02(1.421)$ & 0. \\
\hline J[||II) & 0.012 & 0.007 & 0.007 & 0.008 & 0.002 & 0.007 & 0.002 & 0.002 & 0.01 & \\
\hline Dat $5 \%$ & 0.037 & 0.021 & 0.022 & 0.024 & 0.007 & 0.021 & 0.006 & 0.007 & 0.029 & \\
\hline
\end{tabular}

Figures in parenthesis are Arc Sine Percentage transformed values.

Table.3 Population of gram pod borer [H. armigera (Hubner)] on some pigeonpea genotypes during Kharif 2018-19:

\section{H. armigera larvae per plant}

\begin{tabular}{|c|c|c|c|c|c|c|c|c|c|c|}
\hline Genotypes & ISW & 5th SW & 6th SW & 7th SW & 8th SW & 9th SW & 10th SW & 11th SW & 12th SW & ge \\
\hline T2-901 & $.2(1.095)$ & $.12(1.058)$ & $.19(1.091)$ & $.27(1.127)$ & $0.3(1.140)$ & $.63(1.277)$ & $83(1.277)$ & $1.09(1.446)$ & $.6(1.265)$ & 0 \\
\hline$V \mid L-J 0 L$ & $.06(1.030)$ & $.1(1.049)$ & $.2(1.095)$ & $.3(1.140)$ & $0.33(1.153)$ & $.7(1.304)$ & (1.304) & $1.14(1.463)$ & $.73(1.315)$ & 0.5 \\
\hline 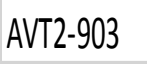 & $.03(1.015)$ & $.19(1.091)$ & $.26(1.122)$ & $.31(1.145)$ & $0.35(1.162)$ & $.84(1.356)$ & $.07(1.356)$ & $1.32(1.523)$ & $.95(1.395)$ & 0.5 \\
\hline AVT2-904 & $.06(1.030)$ & $8(1.039)$ & $.17(1.082)$ & $.29(1.136)$ & $0.28(1.131)$ & $.75(1.323)$ & $.88(1.323)$ & $1.13(1.459)$ & $.73(1.315)$ & 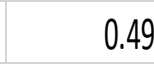 \\
\hline VT2-905 & $.03(1.015)$ & $.09(1.044)$ & $.15(1.072)$ & $.25(1.118)$ & $0.27(1.127)$ & $.68(1.296)$ & $.82(1.296)$ & $1.09(1.446)$ & $.66(1.288)$ & 0. \\
\hline AVT2. & $.03(1.015)$ & $.1(1.049)$ & $.22(1.105)$ & $.39(1.179)$ & $0.37(1.170)$ & $.89(1.375)$ & $1.25(1.375)$ & $1.2(1.483)$ & $.91(1.382)$ & \\
\hline AVT2-907 & $.01(1.005)$ & $.2(1.095)$ & $.14(1.068)$ & $.23(1.109)$ & $0.26(1.122)$ & $.67(1.292)$ & $.9(1.292)$ & $1.06(1.435)$ & $.7(1.304)$ & \\
\hline AAL 13 & $0(1.000)$ & $.06(1.030)$ & & & $0.29(1.136)$ & $.65(1.285)$ & & $.93(1.389)$ & $.64(1.281)$ & \\
\hline SE $(m) \pm$ & 0.011 & 0.014 & 0.001 & 0.003 & 0.002 & & 0.0 & 0.002 & 0.002 & \\
\hline CD at5\% & 0.032 & 0.031 & 0.003 & 0.01 & 0.008 & 0.006 & 0.006 & 0.006 & 0.007 & \\
\hline
\end{tabular}

Figures in parenthesis are Arc Sine Percentage transformed values. 
Table.4 Extent of damage caused by pod pest complex in pigeonpea genotypes during Kharif 2018-19

\begin{tabular}{|c|c|c|c|}
\hline \multirow[t]{2}{*}{ Name of the Entry } & \multicolumn{2}{|c|}{$\begin{array}{c}\text { \% Damage by } \\
\text { H. armigera }\end{array}$} & \multirow[t]{2}{*}{ Grain Yield (Kg/ha) } \\
\hline & Pod & Grain & \\
\hline AVT 1 -701 & $\begin{array}{c}5.67 \\
(13.72)\end{array}$ & $\begin{array}{c}2.40 \\
(8.98)\end{array}$ & 777 \\
\hline AVT 1 -702 & $\begin{array}{c}6.00 \\
(14.14)\end{array}$ & $\begin{array}{c}3.00 \\
(9.92)\end{array}$ & 1000 \\
\hline AVT 1 -703 & $\begin{array}{c}7.33 \\
(15.69)\end{array}$ & $\begin{array}{c}1.70 \\
(7.49)\end{array}$ & 900 \\
\hline AVT 1 -704 & $\begin{array}{c}5.33 \\
(13.33)\end{array}$ & $\begin{array}{c}3.40 \\
(10.56)\end{array}$ & 1233 \\
\hline AVT 1 -705 & $\begin{array}{c}4.67 \\
(12.45)\end{array}$ & $\begin{array}{c}1.90 \\
(7.85)\end{array}$ & 1000 \\
\hline AVT 1 -706 & $\begin{array}{c}5.67 \\
(13.75)\end{array}$ & $\begin{array}{c}3.80 \\
(11.14)\end{array}$ & 1233 \\
\hline AVT 1 -707 & $\begin{array}{c}7.00 \\
(15.33)\end{array}$ & $\begin{array}{c}2.20 \\
(8.42)\end{array}$ & 1433 \\
\hline AVT 1 -708 & $\begin{array}{c}4.33 \\
(11.99)\end{array}$ & $\begin{array}{c}2.50 \\
(9.10)\end{array}$ & 617 \\
\hline AVT 1 -709 & $\begin{array}{c}6.67 \\
(14.94)\end{array}$ & $\begin{array}{c}2.90 \\
(9.83)\end{array}$ & 1233 \\
\hline MAL- 13 (check) & $\begin{array}{c}7.67 \\
(16.04)\end{array}$ & $\begin{array}{c}2.10 \\
(8.11)\end{array}$ & 667 \\
\hline SE(m) \pm & 0.530 & 0.729 & 1.210 \\
\hline$C D$ at $p=0.05 \%$ & 1.587 & 2.183 & 3.622 \\
\hline
\end{tabular}

Figures in parenthesis are Arc Sine Percentage transformed values.

Table.5 Extent of damage caused by pod pest complex in pigeonpea genotypes during Kharif 2018-19

\begin{tabular}{|c|c|c|c|}
\hline \multirow[t]{2}{*}{ Name of the Entry } & \multicolumn{2}{|c|}{$\begin{array}{c}\text { \% Damage by } \\
\text { H. armigera }\end{array}$} & \multirow[t]{2}{*}{ Grain Yield (Kg/ha) } \\
\hline & Pod & Grain & \\
\hline AVT 2 - 901 & $\begin{array}{c}5.67 \\
(13.68)\end{array}$ & $\begin{array}{c}1.68 \\
(7.43)\end{array}$ & 1233 \\
\hline AVT 2 - 902 & $\begin{array}{c}5.33 \\
(13.10)\end{array}$ & $\begin{array}{c}1.64 \\
(7.33)\end{array}$ & 850 \\
\hline AVT 2 - 903 & $\begin{array}{c}7.00 \\
(15.23)\end{array}$ & $\begin{array}{c}2.24 \\
(8.60)\end{array}$ & 767 \\
\hline AVT 2 - 904 & $\begin{array}{c}7.33 \\
(15.59)\end{array}$ & $\begin{array}{c}2.16 \\
(8.43)\end{array}$ & 717 \\
\hline AVT 2- 905 & $\begin{array}{c}6.67 \\
(14.89)\end{array}$ & $\begin{array}{c}1.97 \\
(8.03)\end{array}$ & 748 \\
\hline AVT 2- 906 & $\begin{array}{c}4.00 \\
(11.47)\end{array}$ & $\begin{array}{c}1.09 \\
(5.94)\end{array}$ & 840 \\
\hline AVT 2 - 907 & $\begin{array}{c}3.67 \\
(10.95)\end{array}$ & $\begin{array}{c}0.79 \\
(5.06)\end{array}$ & 1025 \\
\hline MAL-13 (Check) & $\begin{array}{c}6.33 \\
(14.52)\end{array}$ & $\begin{array}{c}1.87 \\
(7.83)\end{array}$ & 1017 \\
\hline $\mathrm{SE}(\mathrm{m}) \pm$ & 1.036 & 0.360 & 1.729 \\
\hline CD at $p=0.05 \%$ & 3.172 & 1.101 & 5.296 \\
\hline
\end{tabular}

Figures in parenthesis are Arc Sine Percentage transformed values. 
Maximum population of (0.69 larva/plant) in the MAL-13 (AVT1) genotype followed in the first week of 2018-19 by AVT1-704 (0.30 larval/plant) AVT1-709 (0.22 larval/plant) AVT1-705, and AVT1-706 \& AVT2-901 (0.20 larval/plant). However, the least number of pod borers found during the 11th standard week in the genotypes AVT1-707 (1.00 larva/plant) and AVT1-708 (1.05 larva/plant). The pooled mean population of gram pod borer was recorded highest in the genotype MAL-13 (AVT1) (check) (0.92 larva/plant) lowest in AVT1-707 (0.41 larva/plant). The rate of pod damage either from pod bug was less than the pod fly damage as from pod borer. In AVT1-708 the cereal yield of different genotypes was from $617 \mathrm{~kg} /$ ha to $1434 \mathrm{~kg} /$ ha with AVT1707genotype. The AVT1-707 was shown to be the most resistant to pod fly damage among the 18 geneotypes screened. For successful pod borer control, this genotype can therefore be recommended for Varanasi farmers.

\section{Acknowledgement}

Dr. Ram Keval, Associate Professor, Department of Entomology, BHU, Varanasi, thanked the author for providing the best possible support and opportunities for their entomological research fields.

\section{References}

AICRP Report (2014). All India Co-ordinated Research Project on Pigeonpea, Project Coordinator's Report Annual group meet 2013. 10-11.

Anonymous. (1992). The Medium Term plan. International Crops Research Institute for the Semi-Arid Tropics (ICRISAT), Patancheru, Andhra Pradesh, India. 110.

Bajia R, Srivastava C P and Keval R (2016) Monitoring of gram pod borer, Helicoverpa.armigera (hübner) through pheromone traps in chickpea, Cicer arietinum L. crop and influence of some abiotic factors on its population. J. Exp. Zool. India 19 (2), 751-755.

Banu, M. R., A. R. Muthiah and S. Ashok (2007). Field screening and evaluation of pigeonpea genotypes against pod borer (Helicoverpa armigera). Pakistan Journal of Biological Sciences, 10(7):1149-1150.

Dhar, V., Singh, S. K., Trivedi. T. P., Das, O. K., Dhandapani, A. and Chaudhary, R.G., (2008). Forecasting of Helicoverpa armigera infestation on long duration in central Uttar Pradesh. Journal of food legume, 21 (3): 189192.

Jaisal, J.K., Srivastava, C.P. and Sharma, R.P. 2010. Resistance in long duration pigeonpea against major insect pests. Ann. Pl. Protec. Sci, 18 (2): 501-502.

Keval, R. Kumar, R, Chkaravarthy, s and Mishra, V.K. (2017). Extent of damage caused by major insect pest on long duration pigeonpea [Cajanus cajan (L.) millsp.] under natural condition Plant Archives 17 (1): 643-346.

Kumar A. and Nath P. 2003. Pest complex and their population dynamics on mediumlate variety of, Bahar. Indian J. Pulses Res, 11 (2): 150-154.

Kumar, A and Nath, P. (2004). Effect of weather parameters on population buildup of pod borers. Indian Journal of Entomology, 66 (4): 293-296.

Lal, S. S. and Yadav, C. P. (1987). Estimation of crop losses in pigeonpea caused by the pod borer complex. FAO Plant protection Bulletin 35 (3):93-98

Lateef,S. S. and Reed, W. (1981). Survey of insect pest Damage in farmer's field in India. International pigeonpea Newsletter. 1:29-30.

Reddy, C. N., Yeshbir, S. and Singh, V. S. (2001). Influence of abiotic factors on 
the major insect pests of pigeonpea Indian Journal of Entomology, 63 (3): 211-214.

Sachan, J. N. (1990). Present Status of Helicoverpa armigera in pulses and strategies for its management. In:
Proceedings of first national workshop on Helicoverpa current status and future strategies, Kanpur, 30-31 August, Kanpur, Indian Institute of Pulses Research, 1992: pp. 7-23.

\section{How to cite this article:}

Rohit Sharma and Ram Keval. 2021. Screening of Pigeonpea [Cajanus cajan (L.) Millsp.] against Gram Pod Borer, Helicoverpa armigera (Hubner (Lepidoptera:Noctuide) in Long Duration Pigeonpea genotypes. Int.J.Curr.Microbiol.App.Sci. 10(05): 768-776. doi: https://doi.org/10.20546/ijcmas.2021.1005.087 